\title{
Typical medullary breast carcinoma: clinical outcomes and treatment results
}

\author{
Andrzej Stelmach ${ }^{1}$, Janusz Ryś ${ }^{2}$, Jerzy W. Mituś ${ }^{1}$, Anna Patla ${ }^{3}$, Piotr Skotnicki ${ }^{4}$, \\ Marian Reinfuss ${ }^{3}$, Elżbieta Pluta ${ }^{3}$, Tomasz Walasek ${ }^{3}$, Beata Sas-Korczyńska ${ }^{5}$
}

Typical medullary breast carcinoma (T-MBC) accounts for less than $1 \%$ of all malignant breast neoplasms, and immunohistochemically is characteristic of "triple-negative" breast carcinoma. The purpose of this study was to describe the clinical characteristics and treatment results for patients with T-MBC treated at a single institution, and discuss the controversial aspects of this very rare form of breast cancer. Analyses was performed in 120 patients with T-MBC who were treated between 1970 and 2005. These cases represent 1.1\% of all (11 270) patients treated for breast cancer during this period. According to TNM classification, 26 patients (21.6\%) were in stage I, 80 patients $(66.7 \%)$ in stage II and $14(11.7 \%)$ in stage III of clinically advanced breast cancer. Involved axillary lymph nodes occurred in just $10(8.3 \%)$ of the patients, and in all cases metastases were observed in 1-3 lymph nodes. All the patients underwent primary surgery. Radical mastectomies were performed on 98 (81.6\%) patients, while the other 22 (18.4\%) underwent breast-conserving surgery (BCS). Radiotherapy was performed in 36 patients (22 after BCS and 14 after mastectomy). Patients with nodal involvement (10 patients) received adjuvant chemotherapy, and 8 patients with hormone receptor expression received hormonotherapy with tamoxifen. The 10-year DFS rate was $90 \%$. Out of 120 patients with T-MBC, only 4 (3.3\%) died from this cancer. We showed that none of the population, neither clinical nor microscopic, had a statistically significant influence on the 10-year disease-free survival rate. Our results are similar to others presented in literature.

NOWOTWORY J Oncol 2017; 67, 1: 7-13

Key words: breast cancer, typical medullary carcinoma, outcome, treatment results

\section{Introduction}

According to the WHO classification, medullary carcinoma is a well-circumscribed tumour (with pushing margins), composed of poorly differentiated cells with scant stroma and prominent lymphoplasmacytic infiltration. The cells of classic medullary carcinoma are characterised by abundant cytoplasm and pleomorphic high-grade vesicular nuclei. They are arranged in syncytial structures which constitute at least $75 \%$ of histologically sampled areas. What is more, the histological texture of medullary carcinoma lacks tubular differentiation [1]. The above-mentioned criteria are similar to those presented by Ridolfi et al. in 1977 [2]. Tumours displaying all these definitive characteristics are classified as (classic) medullary carcinomas. When most, but not all, of these necessary histological features are present, the latest edition of the WHO classification recommends that

${ }^{1}$ Clinic of Surgical Oncology, Maria Skłodowska-Curie Memorial Cancer Center and Institute of Oncology, Kraków Branch, Poland ${ }^{2}$ Department of Tumour Pathology, Maria Skłodowska-Curie Memorial Cancer Center and Institute of Oncology, Kraków Branch, Poland

${ }^{3}$ Department of Radiation Oncology, Maria Skłodowska-Curie Memorial Cancer Center and Institute of Oncology, Kraków Branch, Poland

${ }^{4}$ Deparment of Surgery, St. Raphael Hospital, Kraków, Poland

${ }^{5}$ Clinic of Oncology, Maria Skłodowska-Curie Memorial Cancer Center and Institute of Oncology, Kraków Branch, Poland 
the tumour be classified as invasive carcinoma NST with medullary features.

According to WHO, medullary breast carcinoma (classic, typical) accounts for less than $1 \%$ of all malignant breast neoplasms, and the higher incidence of this carcinoma reported by many authors is due to the inclusion of NST with medullary features among patients with invasive carcinoma [1, 3, 4]. Typical medullary breast carcinoma (T-MBC) occurs more frequently in patients with mutations of the suppressor gene $B R C A-1$ present. The mutation of this gene is more frequently observed [1, 5-11] in patients with T-MBC. Immunohistochemically $\mathrm{T}-\mathrm{MBC}$ is usually characterised by features typical of basal-like carcinomas; they do not express oestrogen, progesterone and HER 2/neu receptors. Hence, they were included in so-called "triple-negative" breast carcinomas $[1,5-7,12-21]$.

The purpose of this study was to describe the clinical characteristics and treatment results for patients with T-MBC treated at a single institution in Poland, and discuss the controversial aspects of this very rare form of breast cancer.

\section{Patients and methods}

Between January 1970 and December 2005, 120 women with T-MBC were treated at the Maria Skłodowska-Curie Memorial Cancer Center and Institute of Oncology in Kraków (MSCCCIO). These cases represent $1.1 \%$ of all (11 270) patients treated for breast cancer during this period. All the histologic slides were re-examined, and a diagnosis of T-MBC was made according to WHO criteria [1]. The stage of cancer was determined using the recently adopted UICC TNM classification for breast cancer at the treatment planning stage. All the patients received initial surgical treatment at the MSCCCIO, and they underwent all other therapeutic procedures, such as postoperative radiotherapy, adjuvant chemotherapy and hormonotherapy in the same institution.

The clinopathological characteristics of patients with T-MBC is presented in Table I.

The youngest patient in the study group was 26 years old and the oldest was 72: the mean age of the patients was 51 and the median age was 52 . A total of 94 of the patients (78.3\%) were aged between 35 and $64 ; 10$ (8.3\%) of the patients were aged below 35 and 16 (13.3\%) were aged above 64. On the other hand, 58 patients (48.3\%) were younger than 51 and 62 (51.7\%) were older than 51 years. A total of 26 patients (21.6\%) were diagnosed with stage I clinically advanced cancer according to the TNM UICC classification, while 80 patients $(66.7 \%)$ were diagnosed with stage II and 14 (11.7\%) with stage III. An examination of the post-surgical material revealed that the breast tumour was less than $2 \mathrm{~cm}$ in diameter in 45 of the patients (37.5\%), ranged between 2 and $5 \mathrm{~cm}$ in 70 patients (58.3\%), and was more than $5 \mathrm{~cm}$ in diameter in 5 patients (4.2\%). Microscopy revealed that metastases in the axillary lymph nodes occurred in just
Table I. The clinicopathological characteristics of patients with T-MBC

\begin{tabular}{|c|c|c|}
\hline Characteristics & No. of patients & $\%$ \\
\hline \multicolumn{3}{|l|}{ Age (years) } \\
\hline$<51$ & 58 & 48.3 \\
\hline$\geq 51$ & 62 & 51.7 \\
\hline \multicolumn{3}{|l|}{ Stage (TNM) } \\
\hline I & 26 & 21.6 \\
\hline$\|$ & 80 & 66.7 \\
\hline IIIA & 14 & 11.7 \\
\hline \multicolumn{3}{|l|}{ Tumour size (pT) } \\
\hline$<2 \mathrm{~cm}(\mathrm{pT} 1)$ & 45 & 37.5 \\
\hline $2-5 \mathrm{~cm}$ (pT2) & 70 & 58.3 \\
\hline$>5 \mathrm{~cm}$ (pT3) & 5 & 4.2 \\
\hline \multicolumn{3}{|c|}{ Lymph node status (pN) } \\
\hline pNO & 110 & 91.7 \\
\hline $\mathrm{pN}+(1-3)$ & 10 & 8.3 \\
\hline $\mathrm{pN}+(\geq 4)$ & - & - \\
\hline \multicolumn{3}{|l|}{ ER status: } \\
\hline Positive & 8 & 6.7 \\
\hline Negative & 112 & 93.3 \\
\hline \multicolumn{3}{|l|}{ PgR status: } \\
\hline Positive & 5 & 4.2 \\
\hline Negative & 115 & 95.8 \\
\hline \multicolumn{3}{|l|}{ HER 2/neu status: } \\
\hline Positive & 15 & 12.5 \\
\hline Negative & 105 & 87.5 \\
\hline Total & 120 & 100.0 \\
\hline
\end{tabular}

$10(8.3 \%)$ of the patients, while in all cases metastases were observed in 1-3 lymph nodes. The analysis revealed no expression of oestrogen receptors (ER) in 112 patients (93.3\%), no expression of progesterone receptors ( $\mathrm{PgR}$ ) in 115 patients $(95.8 \%)$, and expression absence of HER2/neu receptors in $105(87.5 \%)$ patients. The treatment methods used for patients with T-MBC are presented in Table II.

All the patients underwent primary surgery. Radical mastectomies (Halsted during the period 1970-1982, Patey or Madden in 1883-2005) were performed on 98 (81.6\%) patients, while the other $22(18,4 \%)$ patients treated between 1995 and 2005 underwent breast-conserving surgery (BCS). All those patients who underwent $\mathrm{BCS}$ received adjuvant radiotherapy. A dose of $50 \mathrm{~Gy}$ administered in 25 fractions was delivered over the course of 5 weeks to the whole breast using the two tangential fields technique. This was followed by a boost (10 Gy administered in 5 fractions) to the tumour bed. After mastectomy procedures, 14 of the 98 patients (with $\mathrm{pN}+$, and/or $\mathrm{pT}>5 \mathrm{~cm}$ ) received adjuvant radiotherapy at a dose of $50 \mathrm{~Gy}$ in 25 fractions administered to the chest wall with scar and regional (axillary, internal mammary and supraclaviculor) lymphatic areas. Patients with nodal in- 
Table II. The treatment methods delivered in the presented group of patients with T-MBC

\begin{tabular}{lcc}
\hline Treatment method & No. of patients & $\%$ \\
\hline $\begin{array}{l}\text { Surgery } \\
\quad \text { Mastectomy }\end{array}$ & 98 & 81.6 \\
$\quad \begin{array}{l}\text { Breast-conserving surgery (BCS) } \\
\text { Radiotherapy }\end{array}$ & 22 & 18.4 \\
$\quad$ Yes & 36 & \\
$\quad$ No & 84 & 70.0 \\
Chemotherapy & & \\
$\quad$ Yes & 10 & 8.3 \\
$\quad$ No & 110 & 91.7 \\
Hormonal therapy & & \\
$\quad$ Yes & 8 & 6.7 \\
$\quad$ No & 112 & 93.3 \\
Total & 120 & 100.0 \\
\hline
\end{tabular}

volvement received adjuvant chemotherapy according to a CMF (cyclophosphamide, methotrexate, and 5- fluorouracil) schedule. Endocrine therapy with tamoxifen was administered to 8 (6.7\%) patients with PgR and/or ER expression.

Treatment efficacy was measured on the basis of 10-year disease-free survival (DFS) rates. The Kaplan-Meier estimation was used for this purpose. The long rank test was applied to evaluate the significance of the results. The statistical significance level was established at $\mathrm{p} \leq 0.05$.

\section{Results}

All the patients were followed up for a period of at least 10 years (or until their deaths). The median follow-up time was 14 years. The 10 -year DFS rate was $90 \%$.

The relationship between the results of treatment and population, clinical and microscopic characteristics, expression of the c-erb-B2 gene and the presence of hormone receptors are presented in Table III.

As shown in Table III, it was not confirmed in the patient study group whether any of the studied population, clinical and microscopic factors, or any factors analysed immunohistochemically, had a statistically significant influence on the 10-year disease-free survival rate.

The patients' follow-up and the causes of treatment failure are presented in Table IV.

Three patients died from myocardial infarction, two from haemorrhage, one from acute pancreatitis, one from lung cancer and one from infiltrating ductal carcinoma of the second breast. The other patients died as a result of distant T-MBC metastases in the bones, the lungs, the brain and the liver.

To sum up, out of a total of 120 patients with T-MBC in the study group, only 4 (3.3\%) died from this cancer; in all these patients a microscopy revealed metastases in
Table III. Treatment results in 120 patients with T-MBC in relation to population, clinical, microscopic and immunohistochemically characteristics

\begin{tabular}{|c|c|c|c|}
\hline \multirow[t]{2}{*}{ Characteristics } & \multirow{2}{*}{$\begin{array}{l}\text { No of } \\
\text { patients }\end{array}$} & \multicolumn{2}{|c|}{ 10-year disease-free survival } \\
\hline & & No. of patients & $\%$ \\
\hline \multicolumn{4}{|l|}{ Age } \\
\hline$<51$ & 58 & 52 & 89.7 \\
\hline$\geq 51$ & 62 & 56 & 90.3 \\
\hline \multicolumn{4}{|l|}{ TNM stage } \\
\hline I & 26 & 24 & 92.3 \\
\hline ॥ & 80 & 72 & 90.0 \\
\hline IIIA & 14 & 12 & 85.7 \\
\hline \multicolumn{4}{|c|}{ Tumour size (pT) } \\
\hline$<2 \mathrm{~cm}$ & 45 & 41 & 91.1 \\
\hline $2-5 \mathrm{~cm}$ & 70 & 63 & 90.0 \\
\hline$>5 \mathrm{~cm}$ & 5 & 4 & 80.0 \\
\hline \multicolumn{4}{|c|}{ Node status (pN) } \\
\hline pNO & 110 & 102 & 92.7 \\
\hline $\mathrm{pN}+(1-3)$ & 10 & 6 & 60.0 \\
\hline \multicolumn{4}{|l|}{ ER status } \\
\hline Positive & 8 & 7 & 87.5 \\
\hline Negative & 112 & 101 & 90.2 \\
\hline \multicolumn{4}{|l|}{ PgR status } \\
\hline Positive & 5 & 4 & 80.0 \\
\hline Negative & 115 & 104 & 90.4 \\
\hline \multicolumn{4}{|l|}{ HER 2/neu status } \\
\hline Positive & 15 & 13 & 86.7 \\
\hline Negative & 105 & 95 & 90.5 \\
\hline Total & 120 & 108 & 90.0 \\
\hline
\end{tabular}

the axillary lymph nodes. None of the 110 patients with T-MBC without lymph node metastases died of the disease; hence all the patients who underwent breast-conserving treatment survived for 10 years disease-free.

\section{Discussion}

In this study we presented the clinical characteristics and treatment results for patients with T-MBC at the same institution and we discussed the controversial problems relating to adjuvant systemic treatment of this rare breast cancer.

Table IV. The follow-up and patterns of treatment failure in 120 patients with TMBC

\begin{tabular}{lcc}
\hline Follow-up and causes of death & No. of patients & $\%$ \\
\hline 10-year DFS & 108 & 90.0 \\
Cause of death: & & \\
$\quad$ Distant metastases of T-MBC & 4 & 3.3 \\
Other & 8 & 6.7 \\
Total & 120 & 100.0 \\
\hline
\end{tabular}

DFS - disease-free survival 


\section{Clinicopathologic characteristics}

Our analysis proved that in patients with T-MBC:

- the mean age was 51 years (26-72), median - 52 years;

- the percentage of patients with stage I-II TNM was almost $90 \%$;

- the percentage of patients with $\mathrm{pT} \leq 5 \mathrm{~cm}$ and $\mathrm{pN} 0$ was above $90 \%$;

- ER and PgR negative status was observed in more than $90 \%$ of the patients;

- HER-2/neu negative status was observed in almost $90 \%$ of the patients.

Similar population, microscopic and clinical characteristics, as well as immunohistochemically studied factors can be found quite often in the literature, obviously in varying frequency and intensity $[1,2,15,17$, $18,21-30]$. However, it is important to stress that making strict comparisons between the present study group of patients and groups presented by other authors is very difficult and remains a questionable approach, since a T-MBC diagnosis itself is problematic and controversial. It is important to bear in mind the inconsistencies pointed out in the literature when it comes to assessing the type of cancer (T-MBC vs invasive carcinoma NST with medullary features) between pathologies (interobserver), as well as inconsistencies in assessing the same pathology (intraobserver). The WHO itself has stressed the difficulties involved in applying in practice strict T-MBC criteria [1]. Some authors have discussed an overall group of patients with $\mathrm{T}-\mathrm{MBC}$, so-called atypical $\mathrm{MBC}-\mathrm{A}-\mathrm{MBC}$, and even with invasive NST carcinoma with medullary features; some publications from the 1960s and 1970s are in this respect difficult to verify.

\section{Age of patients}

The mean age of patients in the study group was 51 years; similar values have been reported by Vong et al. [31] - 51.7, Wong et al., [29] - 51.0 and Martinez et al. [27] — 50 years; meanwhile, lower values have been reported by Khomsi et al. [23] - 47.5, Vu — Nishino et al. [16] - 47.5, Yilmaz et al. [32] - 48.3, Wargotz \& Silverberg [24] - 45 years, Thurman et al. [22] - 44 years, and Vo et al., which noted a mean survival of as low as 39.2 years [30]. The vast majority of researchers stress that the percentage of cases of $\mathrm{MBC}$ is higher among young patients with lung cancer than it is in older patients [1, 22, 16-18, 28, 33-35]. A study conducted by CASH (Cancer and Steroid Hormone Study) noted that the higher the age, the lower the percentage of patients with MBC; it was highest in the 20-29 and 30-39 age brackets, while among patients aged $40-49$ and 50-54, it was still higher than in older patients [33, 34]. In 1995 Berg and Hunter observed a high percentage of $\mathrm{MBC}$ in young patients, highest among patients aged $<30$; among patients aged $30-34$ it was confirmed in $8 \%$ of cases, among patients aged $45-49$ it was present in only $3 \%$ of cases, and in the $75-79$ age group $-1.5 \%$ [35].

\section{Stage of disease}

A total of $88.3 \%$ of the patients in the study group were diagnosed with stage I or II of the disease according to the TMN classification. This result is in accordance with the observations of many authors who emphasis that patients with this advanced stage of the disease clearly predominate in percentage terms $[2,10,18,21,22,24,25,28-30]$. According to certain authors, patients with stages I and $I^{\circ}$ of the disease represent more than $90 \%$ of the total. For example, Cao et al. report a figure of $94.6 \%$, Anz et al. - 92.3\%, and Zhang et al. $-96.2 \%[18,28,36]$.

\section{Size of tumour in the breast}

In more than $95 \%$ of patients in the study group, the breast tumour (pT) did not exceed $5 \mathrm{~cm}$. Bertucci et al. [6] and Vo et al. [30] reported exactly the same percentage of pT1 and pT2 tumours. Hang et al. reported that tumours $<5 \mathrm{~cm}$ accounted for $92.3 \%$ [28] of the total, while Cao et al. gave a figure of $97.4 \%$ [18] and Flucke et al. - 98.2\% [17]. Meanwhile both Wang et al [29] and Vu-Nishino et al. [16] reported that such tumours accounted for approximately $100 \%$ of their cases.

\section{Microscopic state of axillary lymph nodes}

Micropscopy revealed the absence of metastases in the axillary lymph nodes of $91.7 \%$ of the patients in the study group; in the remaining $8.3 \%$ of cases, metastases were identified in 1-3 lymph nodes. Patients with T-MBC tend to have a lower overall frequency of ALN (axillary lymph node) metastases than patients with invasive ductal carcinoma with medullary features or usual invasive ductal carcinoma $[2,16$, 17, 21, 22, 24, 25, 27-29, 31, 37-40]. Martinez et al. [27] identified pN0 in $71.7 \%$ of patients, Flucke et al. [17] - 75\%, Vo et al. [30] - 76.7\%, Khomsi et al. [9] - 78.8\%, Thurman et al. — 90\% [22] and Zhang et al. [28] - 92.3\%. When nodal metastases are present, they typically involve no more than three lymph nodes [18, 22, 24, 25, 37, 40-42]. Cao et al reported the following observations: $70.2 \%$ of patients with $\mathrm{pN} 0,23.9 \% \mathrm{pN}+(1-3)$ and $5.9 \% \mathrm{pN}+(>3)$, while Thurman et al. noted $90 \%$ of patients with pNO and $10 \%$ with pN+ $(1-3)[18,22]$.

\section{Oestrogen and progesterone receptors and c-erb $B 2$ gene expression}

The general view is that T-MBC indicates negative progesterone and oestrogen receptors as well as an absence of c-erbB2 gene expression $[1,5,6,12,1,16-19$, $27,30,31,37,42-45]$, while no progesterone receptors were identified in $95.8 \%$ of cases and c-erb B2 gene expression was only noted in $12.5 \%$ of cases. Bertucci et al. 
described a group of patients, in $100 \%$ of whom there were no oestrogen receptors and in $96 \%$ no progesterone receptors [6]. Jacquemier et al. presented a study in which they identified negative oestrogen receptors in $89.5 \%$ of patients and negative progesterone receptors in $48.7 \%$ [5]; Matkovic et al. reported percentages of $94.0 \%$ and $83 \%$, respectively [44]. In an analysis of 13 controlled clinical studies, Huober et al. observed negative oestrogen and progesterone receptors in $81 \%$ of patients [26]. The c-erb B2 gene expression was shown to be absent in $100 \%$ of the patients observed by Bertucci et al. [6] and Vang et al. [31], in $94.4 \%$ of the patients studied by Jacquemier et al. [5] as well as in $93.4 \%$ of cases in a study conducted by Flucke et al. [17].

\section{Efficacy of treatment for patients with T-MBC}

Of the 120 patients with T-MBC comprising the study group, a total of $108(90 \%)$ survived disease-free for 10 years. Only 4 (3.3\%) of the patients died as a result of T-MBC, all with metastases occurring in the axillary lymph nodes $91-3 \mathrm{~N}+$ ). None of the 110 patients with T-MBC, in whom no metastases occurred in the axillary lymph nodes, died of the disease.

Table $V$ shows the treatment results for $\mathrm{MBC}$ according to the data from the literature. According to Table $V$ and other data from the literature, the 10-year survival rate for patients with MBC varies between $63 \%$ and $94.9 \%$, while the 5 -year survival rate ranges from $70 \%$ to $92.3 \%$; these significant differences mainly result from differences in the clinical and microscopic composition (T-MBC vs invasive carcinoma NST with medullary features) of the groups of patients being compared [16, 18, 21, 22, 24-27, $29,39,45]$. The vast majority of the researchers stress that the prognosis for patients with $M B C$ is good or even very good, especially in the case of T-MBC, and is significantly better than among patients with invasive ductal carcinoma $[2,5-7,11,13,14,16-18,21-23,25-28,37,40,42$, 45-48]. Koerner provided an analysis of five series, which included a pathologic review of cases recorded as medullary carcinoma $(\mathrm{MBC})$ or as invasive ductal carcinoma with medullary features [37]; fewer than $50 \%$ of the lesions were accepted as $M B C$, and the remaining cases were diagnosed as invasive ductal carcinomas with medullary features or invasive ductal carcinomas [2, 24, 25, 40, 42]. Patients with $\mathrm{MBC}$ proved to have a statistically significant more favourable prognosis than those in either of the other two groups [37].

A study conducted by Cao et al. showed the following 10-year overall survival rates: $91 \%$ for patients with BM and, $81 \%$ for patients with invasive ductal carcinoma. Gjerstorff reported results of $84 \%$ and $63 \%$, respectively $[18,45]$. Meanwhile, Martinez et al. observed 14-year survival rates
Table V. Treatment results in patients with T-MBC

\begin{tabular}{lcc}
\hline \multirow{2}{*}{$\begin{array}{l}\text { Author, reference, } \\
\text { year of publication }\end{array}$} & \multicolumn{2}{c}{ Survival rates } \\
\cline { 2 - 3 } & 10-year & 5-year \\
\hline Rapin V et al. [24] 1988 & $92.0 \%$ & - \\
Reinfuss M et al. [39] 1995 & - & $78.0 \%$ \\
Thurman SA et al. [21] 2004 & $63.0 \%$ & - \\
Vu-Nishino H et al. [16] 2005 & $94.9 \%$ & - \\
Gjerstorff MF et al. [45] 2006 & $84.0 \%$ & $85.0 \%$ \\
Khomsi F et al. [22] 2007 & - & $89.0 \%$ \\
Vo T et al. [29] 2007 & $79.5 \%$ & - \\
Martinez SR et al. [26] 2011 & $78.0 \%$ & - \\
Huober J et al. [25] 2012 & $66.0 \%(14-y e a r)$ & - \\
Zhang J et al. [27] 2013 & - & $92.3 \%$ (6-year) \\
Cao AY et al. [18] 2013 & $91.0 \%$ & - \\
Stelmach A et al. [present] 2016 & $90.0 \%$ & - \\
\hline
\end{tabular}

of $66 \%$ and $57 \%$, respectively, including, $80 \%$ and $73 \%$ for pN0 patients, respectively and $63 \%$ and $49 \%$ for $\mathrm{pN}+$ patients, respectively [27]. Undoubtedly surprising is the fact that the prognosis for T-MBC, despite its "triple negative breast cancer" features, is good or even very good, indeed significantly better than it is for infiltrate ductal breast carcinoma. Most authors think that this is due to the presence of abundant lymphoplasmacytic infiltration that is inseparably associated with this cancer $[49,50]$. Jacquemier et al. as well as Bertucci et al. suggest that this may partly be a result of myoepithelial differentiation T-MBC $[5,6]$.

\section{Treatment of T-MBC}

The current treatment of choice for patients with T-MBC is breast conserving therapy $(\mathrm{BCT})$ supplemented with radiotherapy. This is particularly the case with patients with breast tumours not exceeding $3 \mathrm{~cm}$; sentinel lymph node mapping is an appropriate procedure for staging axillary lymph nodes [37]. It should be stressed that the prognosis for patients with small, node-negative T-MBC is particularly favourable with a 10 -year DFS rate of $90 \%$ or better [2, 24]. In the study group, all 22 patients treated with BCT survived for 10 years disease-free.

Adjuvant chemotherapy can probably be omitted in patients with T1 NO MO TMBC; the indications for systemic adjuvant therapy in other patients are similar to those for non-medullary invasive duct carcinoma.

\section{Conclusions}

1. The population, microscopic and clinical characteristics as well as selected immunohistochemically assessed features of T-MBC are: 
- a mean age of 51 years;

— almost $90 \%$ are stage I or II patients;

- more than $90 \%$ patients had breast tumours (pT) not exceeding $5 \mathrm{~cm}$;

- more than $90 \%$ of the patients had negative axillary lymph nodes;

- no patients developed metastases in more than 3 axillary lymph nodes;

- absence of progesterone and oestrogen receptors expression in more than $90 \%$ of the patients;

- absence of c-erb B2 expression was observed in more than $90 \%$ of the patients.

2. The 10-year disease-free survival rate for the author's own material was $90 \%$. Only $3.3 \%$ of the patients $(4 / 120)$ died from T-MBC, all of them from metastases in the axillary lymph nodes $(\mathrm{N}+1-3)$. None of the 110 patients with no metastases in the axillary lymph nodes (N0) died from T-MBC.

3. The surgical procedure of choice for patients with $\mathrm{T}-\mathrm{MBC}$, is, with the right indications, breast conserving therapy $(\mathrm{BCT})$. Of the 22 patients who underwent $\mathrm{BCT}$ from the author's own material, all survived for 10 years disease-free.

4. T-MBC patients with no metastases in the axillary lymph nodes require no adjuvant chemotherapy.

\section{Conflict of interest: none declared}

\section{Beata Sas-Korczyńska}

Associate Professor

Clinic of Oncology

Maria Skłodowska-Curie, Memorial Cancer and Institute

of Oncology, Kraków Branch

11 Garncarska Street, 31-115 Kraków, Poland

e-mail:z5korczy@cyf-kr.edu.pl

Received: 3 Aug 2016

Accepted: 31 Oct 2016

\section{References}

1. Jacquemier J, Reis-Filho JS, Lakhani SR et al. Carcinoma with medullary features. In: Lakhani SR, Ellis IO, Schnitt SJ et al. (eds). WHO classification of tumours of the breast (WHO classification of tumours, vol.4.). 4th ed., Lyon: IARC, 2012.

2. Ridolfi RL, Rosen PP, Port A et al. Medullary carcinoma of the breast: a clinicopathologic study with 10 year follow-up. Cancer 1977; 40: 1365-1385.

3. Gaffey MJ, Mills SE, Frierson HF Jr. et al. Medullary carcinoma of the breast: interobserver variability in histopathologic diagnosis. Mod Pathol 1995; 8: 31-38.

4. Pedersen L, Holck S, Schiødt T et al. Inter- and intraobserver variability in the histopathological diagnosis of medullary carcinoma of the breast, and its prognostic implications. Breast Cancer Res Treat 1989; 14: 91-99.

5. Jacquemier J, Padovani L, Rabayrol L et al. Typical medullary breast carcinomas have a basal/myoepithelial phenotype.J Pathol 2005;207:260-268.

6. Bertucci F, Finetti $P$, Cervera $\mathrm{N}$ et al. Gene expression profiling shows medullary breast cancer is a subgroup of basal breast cancers. Cancer Res 2006; 66: 4636-4644.

7. Marginean F, Rakha EA, Ho BC et al. Histological features of medullary carcinoma and prognosis in triple-negative basal-like carcinomas of the breast. Mod Pathol 2010; 23: 1357-1363.
8. Shousha S. Medullary carcinoma of the breast and BRCA1 mutation. Histopathology 2000; 37: 182-185.

9. Vargas AC, Da Silva L, Lakhani SR. The contribution of breast cancer pathology to statistical models to predict mutation risk in BRCA carriers. Fam Cancer 2010; 9: 545-553.

10. Eichhorn J.H. Medullary carcinoma, provocative now as then. Semin Diagn Pathol 2004; 21: 65-73.

11. Malyuchik SS, Kiyamova RG. Medullary breast carcinoma. Exp Oncol 2008; 30: 96-101.

12. Rakha EA, Reis-Filho JS, Ellis IO. Basal-like breast cancer: a critical review. J Clin Oncol 2008; 26: 2568-2581.

13. Weigelt B, Geyer FC, Reis-Filho JS. Histological types of breast cancer: how special are they? Mol Oncol 2010; 4: 192-208.

14. Eisinger $F$, Jacquemier J, Charpin $C$ et al. Mutations at BRCA1: the medullary breast carcinoma revisited. Cancer Res 1998; 58: 1588-1592.

15. Ponsky JL, Gliga L, Reynolds S. Medullary carcinoma of the breast: an association with negative hormonal receptors. J Surg Oncol 1984; 25: 76-78.

16. Vu-Nishino H, Tavassoli FA, Ahrens WA et al. Clinicopathologic features and long-term outcome of patients with medullary breast carcinoma managed with breast-conserving therapy (BCT). Int J Radiat Oncol Biol Phys 2005; 62: 1040-1047.

17. Flucke U, Flucke MT, Hoy L et al. Distinguishing medullary carcinoma of the breast from high-grade hormone receptor-negative invasive ductal carcinoma: an immunohistochemical approach. Histopathology 2010; 56: 852-859.

18. Cao AY, He M, Huang L et al. Clinicopathologic characteristics at diagnosis and the survival of patients with medullary breast carcinoma in China: a comparison with infiltrating ductal carcinoma-not otherwise specified. World J Surg Oncol2013; 11:91. doi: 10.1186/1477-7819-11-91.

19. Vincent-Salomon A, Gruel N, Lucchesi $C$ et al. Identification of typical medullary breast carcinoma as a genomic sub-group of basal-like carcinomas, a heterogeneous new molecular entity. Breast Cancer Res 2007; 9: R24.

20. Rakha EA, Ellis IO. Triple-negative/basal-like breast cancer: review. Pathology 2009; 41: 40-47.

21. Wang $X X$, Jiang $Y Z$, Liu $X Y$ et al. Difference in characteristics and outcomes between medullary breast carcinoma and invasive ductal carcinoma: a population based study from SEER 18 database. Oncotarget 2016; 7: 22665-22673.

22. Thurman SA, Schnitt SJ, Connolly JL et al. Outcome after breast-conserving therapy for patients with stage I or II mucinous, medullary, or tubular breast carcinoma. Int J Radiat Oncol Biol Phys 2004; 59: 152-159.

23. Khomsi F, Ben Bachouche W, Bouzaiene $\mathrm{H}$ et al. Carcinome médullaire typique du sein : étude rétrospective à propos de 33 cas. Gynecol Obstet Fertil 2007; 35: 1117-1122.

24. Wargotz ES, Silverberg SG. Medullary carcinoma of the breast: a clinicopathologic study with appraisal of current diagnostic criteria. Hum Pathol 1988; 19: 1340-1346.

25. Rapin V, Contesso G, Mouriesse H et al. Medullary breast carcinoma. A reevaluation of 95 cases of breast cancer with inflammatory stroma. Cancer 1988; 61: 2503-2510.

26. Huober J, Gelber S, Goldhirsch A et al. Prognosis of medullary breast cancer: analysis of 13 International Breast Cancer Study Group (IBCSG) trials. Ann Oncol 2012; 23: 2843-2851.

27. Martinez SR, Beal SH, Canter RJ et al. Medullary carcinoma of the breast: a population-based perspective. Med Oncol 2011; 28: 738-744.

28. Zhang J, Wang Y, Yin Q et al. An associated classification of triple negative breast cancer: the risk of relapse and the response to chemotherapy. Int J Clin Exp Pathol 2013; 6: 1380-1391.

29. Wong SL, Chao C, Edwards MJ et al. Frequency of sentinel lymph node metastases in patients with favorable breast cancer histologic subtypes. Am J Surg 2002; 184: 492-498.

30. Vo T, Xing Y, Meric-Bernstam F et al. Long-term outcomes in patients with mucinous, medullary, tubular, and invasive ductal carcinomas after lumpectomy. Am J Surg 2007; 194: 527-531.

31. Vong JS, Yu AM, Ng DC et al. Reduced numbers of regulatory T cells in breast carcinoma with medullary features. Histopathology 2011; 59: 345-349.

32. Yilmaz $E$, Lebe B, Balci $P$ et al. Comparison of mammographic and sonographic findings in typical and atypical medullary carcinomas of the breast. Clin Radiol 2002; 57: 640-645.

33. Marcus JN, Watson P, Page DL et al. Pathology and heredity of breast cancer in younger women. J Nat/ Cancer Inst Monogr 1994; 1994: 23-34.

34. Claus EB, Risch N, Thompson WD et al. Relationship between breast histopathology and family history of breast cancer. Cancer 1993; 71: 147-153. 
35. Berg JW, Hutter RV. Breast cancer. Cancer 1995; 75 (1 Suppl): 257-269.

36. Anz D, Eiber $S, S c h o l z C$ et al. In breast cancer, a high ratio of tumour-infiltrating intraepithelial CD8+ to FoxP3+ cells is characteristic for the medullary subtype. Histopathology 2011; 59: 965-974.

37. Mitze M, Goepel E. Prognostic factors in medullary breast cancer. Geburtshilfe Frauenheilkd 1989; 49: 635-641.

38. Li Cl, Uribe DJ, Daling JR. Clinical characteristics of different histologic types of breast cancer. Br J Cancer 2005; 93: 1046-1052.

39. Reinfuss M, Stelmach A, Mituś J et al. Typical medullary carcinoma of the breast: a clinical and pathological analysis of 52 cases. J Surg Oncol 1995; 60: 89-94.

40. Dendale R, Vincent-Salomon A, Mouret-Fourme E et al. Medullary breast carcinoma: prognostic implications of p53 expression. Int J Biol Markers 2003; 18: 99-105.

41. Fisher ER, Kenny JP, Sass R et al. Medullary cancer of the breast revisited. Breast Cancer Res Treat 1990; 16: 215-229.

42. Reiner A, Reiner G, Spona J et al. Histopathologic characterization of human breast cancer in correlation with estrogen receptor status. A comparison of immunocytochemical and biochemical analysis. Cancer 1988; 61: 1149-1154.

43. Rosen PP, Lesser ML, Arroyo CD et al. Immunohistochemical detection of HER2/neu in patients with axillary lymph node negative breast carcinoma. A study of epidemiologic risk factors, histologic features, and prognosis. Cancer 1995; 75: 1320-1326.

44. Matkovic B, Juretic A, Separovic V et al. Immunohistochemical analysis of ER, PR, HER-2, CK 5/6, p63 and EGFR antigen expression in medullary breast cancer. Tumori 2008; 94: 838-844.

45. Gjerstorff MF, Benoit VM, Laenkholm AV et al. Identification of genes with altered expression in medullary breast cancer vs. ductal breast cancer and normal breast epithelia. Int JOnco/ 2006; 28: 1327-1335.

46. Milde S, Gaedcke J, Wasielewski R et al. Diagnostik und Immunohistochemie des medullären Uammakarzinens. Pathologe 2006; 27: 358-362.

47. Samir SM, Fayaz MS, Elbasmi A et al. Medullary carcinoma of the breast: ten year clinical experience of the Kuwait cancer control centre. Gulf J Oncolog 2011; 1: 45-52.

48. Gamel JW, Meyer JS, Feuer E et al. The impact of stage and histology on the long-term clinical course of 163,808 patients with breast carcinoma. Cancer 1996; 77: 1459-1464.

49. Sabatier R, Finetti P, Cervera $\mathrm{N}$ et al. A gene expression signature identifies two prognostic subgroups of basal breast cancer. Breast Cancer Res Treat 2011; 126: 407-420.

50. Rakha EA, Aleskandarany $\mathrm{M}, \mathrm{El}$-Sayed $\mathrm{M}$ et al. The prognostic significance of inflammation and medullary histological type in invasive carcinoma of the breast. EJC 2009; 45: 1780-1787. 